Redistributing Agency: The Control Roots of Spot Pricing of Electricity

Daniel Breslau

Virginia Tech

$08 / 11 / 2020$

Please cite published version:

Breslau, Daniel. "Redistributing Agency: The Control Roots of Spot Pricing of Electricity." History of Political Economy 52, no. S1 (December 1, 2020): 221-44. https://doi.org/10.1215/00182702-8718023.

\begin{abstract}
The paper traces the development of the "spot pricing" for electrical power, which has provided the technique for calculating electricity prices in wholesale markets in most of the U.S., and is rapidly becoming the standard in many other countries. The model was first formalized by a group of engineers and economists associated with engineering professor Fred Schweppe, at MIT. From his position as a leading control theorist, well-known in the industry, Schweppe proposed an expansion of control theory that he argued would help break the deadlock in regulatory politics and benefit producers and consumers of power alike. He introduced the approach, which he called "homeostatic control" around 1978 in a seminar of the MIT Energy Lab. Derived by way of a biological metaphor, homeostatic control conceives of a self-correcting system that maintains its equilibrium state in the face of a changing environment. As Schweppe and his collaborators put it, their aim was "an efficient, internally-correcting control scheme" (Schweppe et al. 1980, p. 1151). Homeostatic control marked a departure from the "loadfollowing" approach of system operators, who would constantly adjust the dispatch of power to meet the changing demand, or load. Schweppe's group envisioned bringing consumers of power into the control system by constantly feeding them signals in the form of prices. The MIT team discovered through the contact between economists and engineers, the calculation for determining efficient prices is identical to the calculation used by engineers for meeting system load while minimizing costs. The Lagrange multipliers, or lambdas, derived from the engineering optimization are the best estimates of the marginal cost, and therefore the efficient prices, at each node of the system.
\end{abstract}

Keywords: electricity markets, market design, engineering 


\section{Redistributing Agency: The Control Roots of Spot Pricing of Electricity}

\section{Introduction: Control and the market}

Of the many connections between engineering and neoclassical economics, optimization is a particularly busy portal of commerce between the two fields. Engineers, in their pursuit of efficiency, are preoccupied with maximizing output and minimizing inputs. The market of microeconomics was also fashioned as an optimizing mechanism, optimizing aggregate outcomes among individual optimizers (Arrow 2008). It is therefore not a coincidence that the two arrive at equivalent results. Given the objective of the most efficient distribution, the greatest surplus at the lowest cost given a set of constraints, a central controller and a frictionless market arrive at the same result (Lerner 1947). With the development of mathematical tools the equivalence was strengthened, since the same mathematical equations that had to be solved in order to derive the optimal "program" of a central controller were also the analytic tools for describing the equilibrium outcome in a market economy. The tools used to analyze efficient allocation in a centralized economy, such as the most efficient use of resources in wartime, are identical to the tools for determining how an idealized perfectly-competitive economy (Dantzig 1963; Dorfman, Samuelson, and Solow 1958). And the tools developed for optimizing in cases of centralized control have been readily borrowed as tools for modelling the spontaneous optimization that is accomplished by economies under idealized conditions.

The case that is the subject of this chapter, the design of electricity markets and the development of the pricing technique that is now used in most liberalized wholesale electricity markets, features a more lively and open-ended exchange between these two contexts of optimization. Rather than transferring tools from the context of control to that of economic equilibration, the engineers who led this effort were working on a hybrid that allocated agency 
among centralized controllers, automated and human, and distributed economic actors, thus blurring the distinction between them. As a consequence, they also blurred the respective jurisdictions or engineering and economics. The designed market is a hybrid of the engineer's control system, its explicit algorithm for processing signals and determining an optimal response, and the economist's multitude of distributed utility maximizers. The specific division of labor between control and spontaneous equilibrium is subject to negotiation. Some control processes, such as the filtering of measurements and the estimation of a state space, are delegated to a central calculator. Other processers are distributed to innumerable calculators who, on the basis of price signals calculated by the central controller, conduct their own calculations to reach distributed decisions on production, consumption, and investment.

The hybrid structure of this case is typical of instances of market design, as expressed by the tension between the two components of the term, 'market,' and 'design.' It engages engineers in economic analysis, and economists in the engineering of social institutions (Roth 2002). And it generally involves a negotiated redistribution of agency between a mechanism for centralized processing of information and calculation, and the information processing carried out by market participants. The design of the central mechanism, though often carried out by economists, resembles the engineer's design task, while economic analysis is applied to modeling and anticipating the actions of market participants (Guala 2001). The recent social science literature on market design has treated this relatively new area as the jurisdiction of economists, as they try with varying degrees of success to create institutions that have the properties, especially economic efficiency, of their idealized models (Nik-Khah 2008; GarciaParpet 2007; Breslau 2011). In the current case, however, the techniques, models, and concept of efficiency are provided by a team led by control engineers assuming the role of market designers. 
Because the constraints on optimization in this case are the engineering constraints on the electricity grid, the calculation of prices incorporates the engineers' model of those constraints.

This paper examines the origins and development of the mathematical framework for pricing electric power that today is incorporated in the Locational Marginal Pricing (LMP) approach employed in numerous liberalized electricity markets. The account is based on analyses of the key publications and working papers through which the developmental work evolved and was publicized, as well as open-ended interviews with many of the central participants in the work as well as a range of engineers, economists, consumer advocates, and regulators who were involved in the design of the electricity market and its reception. We will see that the origins of the approach, and even the conditions for its possibility, emerged from the theory and practice of control engineering in the specific historical setting of the U.S. electric power system from the early to mid $20^{\text {th }}$ century. This is not to say that there was a firewall separating microeconomics from the theory and practice of control; engineering training and professional practice drew heavily though selectively on economic theory since the $19^{\text {th }}$ century, and the foundational sources of economics in the works of engineers is well known. The point is that the innovations in pricing that are at the heart of electricity markets emerged from the experience, competence, and professional culture of power system control. Moreover, as we will see, they were initially conceived as innovations in control, with no necessary connection to deregulation, nor justifications in free-market thinking in economics. The engineers who initiated the work sought to incorporate the multitude of customers of electric utilities into the control system, rather than to replace centralized control with a market. Only after the We begin with a historical reconstruction of the central role of system controllers and the calculations they performed to the 
growth of the power system, and how the reforms proposed by a group of MIT engineers responded to a crisis in that system's growth.

\section{The development of the grid and the controller's craft}

Since the work of Thomas Hughes on the subject, the electrical power system has been a paradigm for a socio-technical system, that is a system with mutually interacting and reinforcing components that are both social and technical (Hughes 1983; 1987). But this system is also a dynamic one. The parts do not simply function to preserve a static whole, but put that whole in motion, at times achieving a degree of what Hughes calls technological momentum, as positive feedback loops among the components generates a growth process. Because the growth is the result of so many heterogeneous components, none have the ability to stop it, its momentum is irresistible by the will of the actors. It is not a major extension of this perspective to appreciate that the social actors themselves are, so to speak, caught up in the system. The system constitutes them, their perceptions and dispositions, not to mention their material interests, so that they are the last to conceive of an alternative to the system's dynamism.

The established historiography places technologies at the center of the growth machine. At the heart of the system was a set of generating technologies that seemed to be infinitely scalable, and capable of continual improvements in efficiency. The turbine generator, initially powered by pressurized steam, when introduced in 1920 was an enormous improvement over piston-driven dynamos like those used in Thomas Edison's early lighting plants. It was more compact, lighter, durable, and seemed to be indefinitely scalable, with corresponding improvements in efficiency. The trajectory of these machines, in size and efficiency, permitted a corresponding growth in the load that could be served by large, centralized power stations (Hirsh 1989). The transmission grid, which started as a set of disconnected local systems, through the 
development of universal high-voltage alternating current, with a synchronized frequency, complemented the growth of the generators at its core. Voltages of $150 \mathrm{kVolts}$ by 1920 , and approaching $400 \mathrm{kVolts}$ by mid-century allowed power to be transmitted in bulk over long distances with limited losses. Rotary converters, in the pre-Word War II era, allowed the transmission system to integrate every existing use of power: lighting, traction, and increasingly, industrial heating and machinery. As the system grew and integrated an increasingly diverse set of customers who used power at different hours of the day, the systems achieved greater efficiency and still lower costs. Interties between systems allowed for further economizing as loads were further diversified.

Social organizational innovations also reinforced growth, strengthening the positive feedback. These consisted primarily of a system of regulation, first at the local and state level, and ultimately at the federal level for the regulation of interstate commerce in electric power (Glaeser 1957). Regulation played several important roles for the growth regime. It allowed utilities to be legitimately shielded from competition. It harmonized the growing power system with the financial system by providing a predictable return on investment; assuring that investorowned utilities were "going concerns." This was especially important in reducing risk and the costs of capital in an industry that requires enormous up-front investments relative to modest revenue streams. But for its success, regulation also depended on the continual advance of the growth regime itself. Regulation is an adversarial process, pitting conflicting interests of producers and multiple groups of consumers. A successful regulatory system is one that contains those latent conflicts. As many have commented, the best friend of regulators in this regard was the continual growth of the system, with continual improvement in efficiency and reduction of costs (Anderson 1981; Gormley 1983). 
The system was further buttressed by innovative financial techniques. From its early years, electric power was an outlier among major industries in the size of initial investments relative to the revenue streams created by those investments. The enormous initial costs of power plants and transmission lines introduced a chronic problem of attracting capital. Because of the long planning and construction horizons and the much longer duration it would take to recover investments after a plant was built, investors were acutely sensitive to risks. Even within a system of regulation that allowed investors to recover the costs of plants by charging their customers, capital flowed into the industry slowly. Regulation, by protecting smaller utilities from competition, could also put up a barrier to consolidation (Hausman and Neufeld 2011). The growth envisaged by the developers of the power system would require a financial structure to overcome the risks and to channel investment to the grid. Although the Commonwealth Edison magnate Samuel Insull is often credited with developing the industry's financial structure, as with other features of the system, the investment grid was the result of a set of nearly simultaneous and overlapping innovations that eventually emerged into a financial structure that was isomorphic across the industry (Lambert 2015; Hughes 1983).

The techniques for pricing electricity to final consumers also reinforced the growth regime. Regulation determined utitilities" "revenue requirements" for the sake of recovering capital investments, providing a return adequate to attract capital, and covering the industry's variable production costs. But the tariff structure, by which utilities would be allowed to meet their revenue requirements was the result of a separate set of considerations. Beginning in the years of adoption of electric utility regulation, between 1905 and 1915, utilities were allowed to satisfy their revenue requirements through a system of prices that discriminated across classes of customers, but which were designed to maximize market penetration, without regard to 
improving the efficiency with which the utility's resources were used. For industrial and commercial customers, this consisted of a rate consisting mostly of a demand charge based on the customer's peak use of power during the billing period, with a small charge for each unit of power consumed. For residential customers, more numerous but each with relatively small demand, utilities were granted a tariff based almost entirely on a per kilowatt-hour "volumetric charge." Notably, despite the existence of metering technologies that could track each customer's contribution to peak demand, a rate system that would charge based on time-specific use was roundly rejected by the largest players in the industry (Yakubovich, Granovetter, and McGuire 2005). Efficiency could be achieved through the extension and diversification of the system; prices should not inhibit growth. For large customers, linking their bill to their own peak use, and thus the capital costs of supplying power through their won isolated facilities, encouraged their decision to connect to the utility's grid (Neufeld 1987).

\section{Control for growth}

A full accounting of the elements of the growth model must add to these technological and institutional elements the knowledge and practices of the human controllers who operated the system in real time. As Julie Cohn has recently described in acute detail, the growth regime that persisted for the first seventy years of the $20^{\text {th }}$ century would not have been possible without the continual development of techniques for controlling the flows of power on the everexpanding grid (J. A. Cohn 2017). The economic logic of interconnection was irresistible due to its massive effects on load factors and efficiency. The sheer growth of power systems, by expanding the system's geographical footprint, diversifying load, and diversifying power sources, provided the potential for new economies, even as load was left to develop according to its own logic. But the realization of those efficiencies required much more than adding an 
interconnection to the physical grid. These investments presupposed the ability to control flows of power in a way that would realize their benefits and allow for continued integration and growth of the grid.

An essential element of the growth regime, and the what Hughes calls the momentum of this socio-technical system (Hughes 1987), was therefore the work of system controllers. The engineers operating the system, along with the devices developed to assist them, allowed the efficiencies of larger and more diversified systems to be cashed in. They accomplished this primarily through the practice of economic dispatch, or "economy loading." Economic dispatch is the practice of meeting the current load using the lowest cost combination of generating sources. Often, the practice is described in terms of a stack of generators, arranged in order of cost per unit of power output, for instance dollars per kilowatt-hour, from lowest to highest. At low loads, operators will dispatch only the lowest cost sources, such as hydropower and nuclear. As load increases, due to seasonal factors, or simply the daily cycle, more costly sources will be dispatched, coal and natural gas, with inefficient but quickly activated "peaking" generators the last to be called on, as their name suggests, during the small number of hours when demand for power, or load, is at its peak.

Early attempts at economic dispatch, during the first half of the twentieth century, proceeded by simply considering the generators on a system in terms of their heat rates, the energy input, measured in BTUs, required to generate a unit, usually a kilowatt-hour, of power. The lower the heat rate, the more economical the generating unit. Early practices, on relatively small power systems, consisted of considering the power plants in terms of their heat rates, dispatching the most efficient units first, until they were producing power at their maximum capacity, and then successively dispatching less efficient units as the system's total load 
increased (Stahl 1931). In a process that would be repeated past mid-century, analyses soon showed that this technique was suboptimal, that it did not come close to the most economical use of resources. An improved approximation relied on proportionally dispatching plants as load increased, with a larger but constant proportion of the additional load coming from the more efficient plants.

With the growth and increasing interconnection of power systems, economic dispatch became a problem for calculation, for an explicit numerical result, rather than a practical skill of adjusting the output in response to changing load. As systems grew, controllers had to increasingly take into account the features of the transmission system, particularly line losses, which are a function of the length of the transmission line, and the safe operating capacity of transmission lines. The same features that made the power system increasingly economical made the control problem increasingly complex. In order to continue to realize the efficiencies of a larger and more integrated grid, controllers had to solve increasingly complex optimization problems. Before the availability of digital computers to calculate optimal dispatch, power systems used analog computers that (check Cohn book here_ Greater computing power and advances in calculation techniques, chiefly linear programing, extended the capacity of controllers to realize lowest cost dispatch on an every-growing and diversifying grid (J. Cohn 2015). Dispatch starts months in advance, with load forecasts based on weather forecasts, economic analyses, historic growth, new construction of plants and planned outages or retirements of existing plants. Operators construct day-ahead schedules specifying which generating units will be committed the following day, what levels of generation will be required for each hour throughout the day. And engineers do not simply dispatch generators according to a queue, by which the lower-cost generators are operating at capacity before a higher cost unit is 
dispatched. The efficiencies of generators vary depending on their output. So, in dispatching plants, engineers need to compare alternate sources based on their current output and the cost of drawing an additional unit of power from them. And they must take into account the location of the plant, which affects their cost through the effects of grid congestion or the losses of power when it is transmitted over long distances. Thus the art and science of economic dispatch is really a process of calculating the output of each generator on the system, given its location, operating characteristic, so as to serve the existing load at the lowest cost.

\section{Crisis of the growth model}

When historians of the power system refer to the growth regime or the growth model, they are implying that growth, and the expectation of growth, was a constitutive feature of the industry and its system as a whole. As Hughes hinted with the concept of technological momentum, it was inherently a dynamic system. Rather than a sequence of static equilibria, the system operated at any moment only with the promise of future growth. Its financial structure was predicated on a predicted path of growing load and revenues. Regulators required growth forecasts, which they scrutinized closely, when granting permits for new investments in power plants, allowing the developer to recover the cost of the investment by billing their customers. The rate structure lacked economic justification if one views the system in static equilibrium; it was inherently a forward-looking structure, which could be justified only in the way it facilitated rapid market penetration. And the commercial peace in relations of producers to consumers was likewise made possible and guaranteed by the growth model. The power of the industry in regulatory proceedings, which makes the industry a paradigmatic case of regulatory capture, was 
tolerated by customers and political authorities only because of the promise of continued growth, efficiency, and reduced costs.

Beginning in the middle of the 1960 s, this regime of growth in the electric power system in the US reached an impasse (Hirsh 1999, 55-70; Lifset 2014b). Improvements in efficiency had arrived at a plateau as generators approached the theoretical limit of 48 percent thermal efficiency. In an effort to wring more power out of each dollar invested, utilities attempted to construct ever larger power plants, also finding a declining marginal return as the larger designs raised new problems of maintenance and reliability. The innovation of dual-cycle turbines, which reused waste heat from combustion turbines to power a second, steam-driven, turbine, squeezed a few additional percent of efficiency, but likewise arrived at what is still recognized as a hard limit. The "last hope" of a system founded on continual growth, nuclear power, likewise failed to sustain the trajectory of cost economies of previous decades as the cost of building nuclear plants rose multiplicatively. The environmental movement, which had its first successes in legislating protections by the late 1960s, introduced further limitations on the continuous growth model. Finally, the crisis in supplies of oil and natural gas brought higher costs of generating electricity, since generation using these two fuels had proliferated in the previous decade owing to the abundance and low prices of oil and gas.

As is typical of a crisis, elements of the existing system that were taken for granted, and were even necessary for the system's growth, are redefined as problems. A constitutive feature of the power system had been the practice of treating short-term load, the demand for power at any moment, as a given, as an exogenous condition to which system operators had to adjust. As mentioned earlier, the pricing system adopted in the early $20^{\text {th }}$ century enshrined load following, as did the entire craft of the system operator, and the marketing of electric power that allowed the 
grid to cover the North American continent. This basic condition shaped the professional outlook of operators, as well as the tools and techniques at their disposal. The load-following character of the power system, which had been eagerly adopted under the growth model, was now seen as an obstacle to the realization of efficiencies. The ferment of pricing ideas, and a combined intellectual and practical disruption of existing pricing systems, corresponded exactly with the crisis of the growth model. The literature blossomed in the early 1970s, at the same time as utilities, without inspiration from formal economic analyses, initiated small scale programs and experiments in varying the price of power to induce greater efficiencies in the timing of consumption.

\section{Fred Schweppe and the MIT Group: A Control-engineering Solution}

It was this crisis of the growth model that concerned a group of engineers at MIT in the 1970s, as they focused their attention on finding new efficiencies within the control system. They were acutely aware that this problem was simultaneously technical and political, and advocated for their approach on the grounds that it would transcend what had become a zero-sum regulatory game between utilities and their customers. They motivated their far-reaching reform with a comprehensive critique of the historical legacy of the growth model:

The failure of most present-day utility-customer transactions to meet today's needs can be traced to their historical foundations. They were established by individuals unconcerned with power system control and operation, during a time when communication and computation were very expensive, when there was less incentive to use electricity in an efficient fashion, and when cross-subsidies were of limited concern to society (Fred C. Schweppe et al. 1988, 3-9). 
The control engineering reform would address the technical and social impasses of the power system. On one hand, it meant refinements to the control system that would boost capacity factors and lower costs. On the other hand it would restore peace to relations between utilities, their residential customers, and even more importantly, their commercial and industrial customers (Lifset 2014a; Hirsh 1999). It was the interruption of the growth regime that had surfaced tensions that had been only latent as long as rates continued their downward trajectory. The solution proposed by Schweppe's group, rooted in practices of power system control, was more comprehensive, even radical, than the many proposed reforms that were confined to tariff design.

At the center of the MIT group was the control engineer Fred Schweppe. First joining MIT as a member of the Lincoln Laboratory, an R\&D shop working exclusively on US Department of Defense contracts (Freeman and Lincoln Laboratory 1995). At the Lincoln Lab, Schweppe would likely have been involved with its central pursuit, the development of missile defense systems. Here the conception of the control problem as a system of stochastic differential equations would have been a common currency, as would have been the representation of that system as a state space (Bennett 1993, 202-3; MacKenzie 1990).

With his move in the mid-1960s to the Department of Electrical Engineering, and the Energy Lab, Schweppe quickly took on the task of bringing practice in the operation of power systems to the standards of control engineering and the capacities of advanced computers. The foundational task in this project was to reconstruct the power system as an object of state-of-theart control theory and practice, namely, as a state space. Boumans sketches the history of these techniques in his contribution to this volume. An entire power system, such as a regional grid under the control of a monopoly utility, had to be represented as a vector of state variables from 
which one could, with the aid of computers, derive the power flows between all nodes, or buses, on the grid. By representing the power system as a state space, where the state variables represent the voltage magnitudes and phase angles at every bus on the system, Schweppe could import techniques of filtering, estimation, and prediction from control engineering.

By 1968, Schweppe and a small number of collaborators had developed an algorithm for power system state estimation using weighted least squares. The technique allowed system controllers, human and computers, to derive the best estimate of the power flows across an entire system. Controllers needed to know this state, captured in a vector of voltages and phase angles of all buses in the system, in order to plan economic dispatch and to maintain security. Previously, controllers would construct a representation of the full set of power flows using metered readings of the power being injected into the system removed from the system at each of the buses. But, especially with the increasing size and complexity of these systems, this "powerflow" approach was prone to endemic sources of error. A single missing or flawed meter would, and often did, invalidate the entire power-flow study. Schweppe saw that the problem of representing the state of the power system was analogous to many control engineering problems, once the system was understood as a state space. Rather than rely on a complete set of power flow measurements, the state could be estimated from a large quantity of incomplete, redundant, and noisy measurements. These included injections of power, data from line flow meters, and the status of switches throughout the power system. Combined with the vast computing power now available to controllers, Schweppe's technique provided a far-superior snapshot of the entire system. The technique soon became a standard feature of computational methods in powersystem control (Abur and Gómez Expósito 2004; Wu 1990; Fred. C. Schweppe and Wildes 1970). Based on the state-space representation, controllers could then use dynamic programing to 
find the optimal, economic dispatch (Grainger and Stevenson 1994). It was through the perspective that Schweppe and his associates viewed the combined technological and political impasse of power systems.

Schweppe and his group at the MIT Energy Lab targeted the load-following nature of power systems, which had been a deeply embedded, and usually unspoken, assumption of the growth model of power systems. Initially, with the adoption of a time-invariant pricing scheme in the early twentieth century, load-following was a deliberate policy, driven by the growth model. Utilities chose load following due to their preference for growth and market penetration over efficiency. As long as efficiencies were realized elsewhere, load following would allow for unbridled growth (Yakubovich, Granovetter, and McGuire 2005). But as the growth model, figuratively and literally, ran out of steam, the implicit assumption that load should be an exogenous input, allowed to develop and change according to consumers' needs, and that it was the power system's imperative to meet it, was made explicit and problematic. Utilities had relied on diversification of load to realize better load factors and greater efficiency. But the slow growth of the system indicated that the limits to diversity were also being reached. And this meant that the role of diversity in improving load factors was also near exhaustion. Engineers, economists, and other would-be reformers now identified load following as an obstacle to higher load factors and lower costs. In the longer term, systems had to be prepared for a peak load that was much higher than the load that had to be served most of the time. The system required enormous investments in generators that were used for only a small proportion of the time. In the shorter, day to day and hour to hour scale, load following led to suboptimal use of resources and controllers scrambled to meet random changes in load, and responses to frequency changes in the grid often departed from the most economical use of available resources. The low capacity 
factors of the existing fleet of power plants, indicating their low total output relative to their full capacity, had become a frontier in the search for efficiencies.

\section{Homeostatic control}

Equipped with the state-space approach to the power system, Schweppe proposed a comprehensive solution that amounted to a radical change in the control system at the heart of the power grid. From his position as a leading control engineer, Schweppe sketched an expansion of control theory that he argued would help break the deadlock in regulatory politics and benefit producers and consumers of power alike. He introduced the approach, which he called "homeostatic control" around 1978 in a seminar of the MIT energy lab. Homeostatic control is derived from a biological metaphor, that of an organism. The organism maintains its internal state in the face of a changing environment. For instance, it can refer to the way that organisms maintain their body temperature as the environmental temperature changes unexpectedly. When the environmental temperature increases, temperature receptors send information to a controlling device, the central nervous system. The control center then sends control signals to the units of the organism, generally in the form of hormones through the endocrine system, or through quicker nervous impulses. Through processes of negative feedback, the system, a living organism, is returned to its initial homeostatic state. Schweppe defined his task as the application of this kind of logic to the electric power system. The kinds of environmental disturbances to this system could be rapid increases in temperature, and the increased load as home, commercial, and industrial cooling systems are added to the existing background demand for power. Or, a large generator could experience problems, or be shut down unexpectedly. Downed transmission and distribution lines can cause a local system failure. In all of these cases, changes in the system environment are registered as changes in the system's frequency, or changes in flows of power. 
Receptors, to adhere to the biological metaphor, monitor frequency and power flows and can either respond locally or convey information to the system's nerve center.

As Schweppe put it, his aim was "an efficient, internally-correcting control scheme" (Schweppe et al. 1980, p. 1151). Schweppe initially approached the issue with respect to the classic problem of frequency control. Frequency, like body temperature or blood pressure, must be maintained within a narrow range for the power system to operate. Sudden changes to load or to output will upset the balance of load and generation and reduce frequency, if load exceeds generation, or less often increase frequency with a flux of generation relative to load. Frequency regulation had been a purely load-following affair, accomplished through quick adjustments in generator output. In a presentation to the Utility Systems Program seminar within the Energy Lab, Schweppe introduced the idea of homeostatic control as a way of bringing load, the consumers of electric power, into the frequency regulation problem. He proposed sending frequency signals to electricity-using devices that would then adjust their load to regulate frequency - reducing load or even shutting off when frequency was low and resuming when frequency was marginally above the system frequency of $60 \mathrm{~Hz}$. Joined by colleague Richard Tabors, an economist trained in Operations Research, and a group of engineers and graduate students, the group developed this concept into a proposed device called a FAPER, or Frequency Adaptive Power Energy Rescheduler. The FAPER only needs to monitor the local frequency; the frequency becomes a signal. It would work in a way that is analogous to automatic governors that had been placed on generators since the early $20^{\text {th }}$ century, and would replace those governors. In response to changes in frequency, the FAPER would cycle selected powerconsuming equipment on and off. A fleet of FAPERs distributed across a power system's customers would reduce costs for the system by obviating the need for governors on power 
plants to continually adjust to changing frequency, and the need for automatic generation control for a control area of the grid. They reasoned that this would largely do away with the problems confronted by generations of engineers, of how to maintain scheduled flows on tie-lines while regulating frequency. It would liberate the system to simply serve load at the lowest cost, without unexpected departures from the lowest cost dispatch for the sake of frequency regulation. The system's homeostasis, the biological metaphor for maintenance of standard frequency, would be spontaneously realized by a myriad of mutually sensing and adjusting agents, the FAPERs themselves. The paradigm case for application of the FAPER was electric heating, for both industrial applications and residential space and water heating. Heating, the Schweppe group argued, requires energy rather than power; the demand is for a fixed quantity of energy over a time interval. Unlike an electric motor, that uses electricity for power, and requires adequate power at the moment that it is functioning, as long as heating elements have heated within an acceptable range, they can be cycled on and off randomly while maintaining temperature within that range (F. C. Schweppe et al. 1980). Energy-using applications, through the FAPER, could easily adjust their load in order to regulate frequency. It is worth noting that, despite the resemblance, there is no evidence of

\section{Spot pricing}

The logic of the homeostatic metaphor lent itself to frequency regulation, but soon the group around Schweppe begin mapping the metaphor onto the role of price as a control signal. The shift in focus to spot pricing corresponded with the addition of a Harvard-trained engineer, Michael Caramanis, and Roger Bohn, an economics Ph.D. student at Harvard's Sloan School of Business, to the group. While the FAPER involved the response of distributed automated devices, the use of price signals brought homeostatic control into the domain of economic analysis. As 
load increased, customers would be signaled, through prices, to reduce load. Thus customers would be brought into the control system. Load data would be processed through state estimation models to provide a signal to controllers who would calculate economic dispatch orders. Customers would be signaled of the state of the system through prices. The combination of these complementary control functions would maintain the system as efficiently as possible within its secure operating limits. It is worth noting that homeostatic control has some clear affinities with economic ideas, particularly those in the Austrian tradition dealing with self-organization. The turn to the use of prices to achieve spontaneous and optimal control of the power system echoes von Mises' catallactics as well as Hayek's ideas about spontaneous order. But these affinities are almost certainly post-hoc, with Schweppe's inspiration coming from the cybernetic theory that had been so important for mathematical engineering, and was noted as early as Wiener's influential first book on the topic (Wiener 1948, see also Boumans, this volume). Boldyrev (this volume) points to another, apparently independent case, of metaphorical extension of the biological organism to engineering control systems.

Homeostatic control was adopted by the group as a generative principle for a series of papers distributed among the core members of the group. In their initial presentation of homeostatic control, the authors refrained from advocating a specific method for calculating prices. Their preoccupation was not with optimal price signals, but with a range of possible pricing systems, to accomplish a range of control objectives. All the proposed pricing alternatives had the general property of increasing prices as the demand for power increased. But, recognizing that the monopoly utility was not a market, that prices were the product of a central calculator and not countless interactions among buyers and sellers, they understood the pricing method as a policy decision rather than a spontaneous outcome of an impersonal market 
equilibrium. For instance, one proposal based prices on the average total cost for the entire system, combining capital costs with average variable costs (F. C. Schweppe et al. 1980, 1157). Selection of a pricing algorithm would ultimately be based on the desired effect of pricing. Spot pricing was therefore initially an administrative procedure. The electricity marketplace was a space in which a central calculator, the computer that monitored the state of flows on the system, would iteratively derive prices from the state of the grid. The load would then respond to the prices, and in iterative fashion, the new state would provide the basis for updated prices.

With addition of Caramanis and Bohn, the group pivoted from pricing as an element of homeostatic control to the calculation of optimal spot prices. They had now joined the idea of prices as a control signal with welfare economics results on the efficiency of marginal cost-based pricing. The terminology, too, was shifting, as papers from the group gradually ceased to evoke homeostatic control, and adopted the term 'spot pricing.' The term was an apt one in distinguishing the group's recommended approach from virtually all other pricing systems then in use, including the introduction of time-varying prices on a limited scale (Reynolds and Creighton 1980). Even the experiments in time-varying prices in France, described by Yon (this volume), based price calculations on historic load curves. Spot pricing based prices strictly on the current state of load, thus extending the system operator's perspective, the system as a static state-space of power flows, to the calculation of prices. As Caramanis, Bohn, and Schweppe argued in the initial exposition of the approach, spot pricing was a kind of limit to which other proposals for time-varying prices had aspired, but without eliminating remaining inefficiencies. Spot pricing "is shown to encompass and achieve more fully the objectives of rate structures and load management techniques proposed so far" (M. C. Caramanis, Bohn, and Schweppe 1982, $3234)$. 
Economic theory alone was therefore insufficient for deriving the prices that economic theory prescribed. The task required a thorough knowledge of the physical limits and engineering practices of the power grid, and the mathematical representations of the state space, the grid and its power flows. And it is from those practices and that knowledge that Schweppe and his associates derived a pricing system that would ultimately have an economic justification. The prices were based on quantities that are derived when the state is estimated and the optimal loading, the economic dispatch, of the system is found. In the solution to a problem of optimization under constraint using any of a range of methods employing Lagrange multipliers, each constraint is multiplied by a figure representing the incremental change in the objective function with an incremental relaxation of the constraint. In the case of optimizing dispatch of electric power, the paramount constraint is the total load - the quantity of power demanded, with other constraints due to the configuration and safe operating limits of the transmission grid. When the objective function is for total cost, as in the case of economic dispatch, these Lagrange multipliers, conventionally denoted by the Greek letter lambda, are estimates of the cost of an incremental relaxation of a constraint. For purposes of economic dispatch, controllers are most interested in the multiplier that represents the additional cost of one additional unit of load. System controllers carefully tracked this "system lambda" as a way of gauging the load relative to the system's resources; it represented the incremental cost, the shadow price, of providing a particular load, usually the incremental cost of the most expensive generator dispatched at a given moment. They could also calculate the effects of congestion on costs by lambdas indicating the shadow price of congestion at a particular location on the grid. Schweppe, et al., in their book on spot pricing, noted that the equations they developed for calculating prices at each system bus are analogues of the tools of system operators: "Readers with a power system 
background in economic dispatch and optimal load flow (with line flow constraints) will find that the equations of this chapter look familiar. This is to be expected, since such power system theory motivated their development" (Schweppe et al. 1988, p. 175). In a limited sense, the central controller embodies Walras's auctioneer, announcing prices each period. But this controller is more than an auctioneer, since, in addition to calculating equilibrium prices, she must plan optimal dispatch, taking into account not only the bid schedules of participants, but the range of generating resources, the physical configuration of the grid, and its safe operating limits.

Schweppe's team recognized that they had leveraged the equivalence of optimization via central control and optimization of a perfectly competitive market. The centralized optimization could supply the prices that would theoretically be arrived at by a competitive market. And instead of feeding those signals to the central controller, they could be turned into price signals for electricity customers. In each one-hour time period, prices would be updated based on load at the end of the previous time period, so demand during each hour would respond to prices at the beginning of the hour and would then be used to derive the price for the next hour. In an interview with the author, an economist on Schweppe's team describes how the pricing problem recapitulated the engineering problem: "And essentially the prices that came out of it were the shadow prices of the engineering constraints on the electric power system. So that was the theory. We wrote down all the key constraints on the power system, and then we set them up as a maximization problem and looked at their shadow prices. And then we said well what if you interpret these shadow prices as real prices and actually start applying them to things. Can you control the power system in this way?" The same economist certified the result: "I was able to bless it and say yes this was consistent with economic theory in all regards." (Michael C. Caramanis, Schweppe, and Tabors 1983). 
The "marketplace" envisioned by the Schweppe group was decidedly not a market in the economic sense. It lacked basic features of a market, and is therefore better described as a pricing model.. Revenues based on marginal costs are likely to be insufficient to cover the industry's large fixed costs, particularly for generators at the margin. Later electricity market proposals expected that scarcity rents, during periods of peak demand when prices could rise to multiples of the marginal cost of generation, would provide the revenues to cover fixed costs. The MIT group proposed a more direct solution. Those investments would still be subject to a regulatory process, where utilities would seek approval for new plants, and those plants would become part of their rate base. The spot pricing model included an adjustment for "revenue reconciliation," a correction that is not a part of any liberalized electricity model today, to assure that total revenues received by a utility would cover their revenue requirements, namely their costs plus a return on investors' capital. Regulators would no longer approve the specific short-term rate that was charged to customers, but would approve the mechanism for calculating prices, and would justify total revenues in terms of the utility's "rate base." This also meant that investment in new power plants would continue to be subject to a regulatory process. In the chapter on revenue reconciliation, Schweppe et al. proposed a menu of possible ways to force the revenues paid by consumers at spot prices to equal the utility's revenue requirement as determined in the regulatory process. Some of these involved recalculating prices by including the revenue requirement as a kind of reverse budget constraint; total expenditures of customers were constrained to go no lower than the revenue requirement. However, the authors recommended an approach based on a revolving fund, in which revenues above the requirement would be deposited, and would be debited in case of a shortfall in revenues. This solution would Thus customers would still be presented with prices approximating short-term marginal costs. 
It is possible that the provision for revenue reconciliation was added in anticipation of objections from utilities, who would naturally be concerned that the spot pricing systems would not necessarily deliver returns to their investors or cover their own operating costs. As one of the authors reflected, in a 2013 interview, "we knew that we were introducing distortions into the prices and that would affect behavior. But everybody who we talked to about deregulation said that no existing utility is willing to play that game unless it can pay off its sunk costs." This concern may have been prescient, as the question of revenue adequacy has been, and continues to be, one of the most contentious political issues around electricity markets. When competitive wholesale markets were instituted in parts of the U.S. a decade after the publication of the spot pricing book, no revenue reconciliation was contemplated, since they would defeat the purpose of competition. It was expected that generators at the margin, if they were truly necessary, would recover their costs during periods of peak demand, when prices would rise well above their marginal costs, yielding "scarcity rents." But the market participants and regulators continue to struggle over the adequacy of market revenues for supporting necessary investment (Breslau 2013).

\section{Selling the model}

Tabors assumed the role of the public "face" of the spot pricing program, activating a network of connections in an effort to scale up the framework of spot pricing. Schweppe died unexpectedly in 1987, but the remaing members of the spot pricing group continued these effort through a consulting firm they formed, Tabor, Caramanis, and Associates, in 1988. They consulted with electrical utilities, regulators, large industrial electricity customers, and industry groups. Their efforts to interest engineers, through the industry-funded Electrical Power Research Institute were not successful. Electrical engineers, and their organizations, resisted the 
concept of homeostatic control, and later the proposal for marginal-cost based spot pricing. This can be understood as simultaneously a matter of shielding their professional jurisdiction, and responding to an affront to their intellectual outlook. When Schweppe and his associates, principally Richard Tabors, presented their model to the Electrical Power Research Institute, "we got a pretty dramatic cold shoulder out of EPRI. There are some incredible quotes from the number two guy at EPRI, who came to the Foxboro conference, and wrote us a letter back and said that as far as he was concerned, spot pricing, or, in those days, homeostatic control, was the analogue of giving everybody on a 747 a joystick and expecting them to be able to land the airplane." Engineers, concerned above all with the secure operation of the system, chafed at the idea of transfering control of flows of power to the multitudes of customers. Because the system had developed with the embedded assumption of load-following, their procedures depended on a highly predictable load. If the response to prices were to invalidate their planning, including the advance commitment of generating units and day-ahead economic dispatch plans They didn't trust the ability of the proposed system to predict the response of consumers to price changes. The redistribution of agency recommended by Schweppe and his colleagues went too far.

The response from electric utilities was not much more positive. The initial efforts of the Schweppe group to find allies was focused on utilities, and trying to sell them on instituting spot prices. The conviction all along had been that spot prices would save money for both utilities and their customers, but utilities were very hesitant to restructure their pricing and billing practices in a way that could make their revenues less predictable. The group worked briefly with the Southern Company, then and now one of the country's largest regulated utilities, as well as Niagara Mohawk, a utility in New York State, now a subsidiary of the UK-based National Grid. 
At best, firms such as Detroit Edison were willing to pilot spot pricing for selected groups of very large customers.

Potential adopters in industry were not difficult to identify. These were industrial firms with electricity-using processes that could be scheduled at any time. In Schweppe's words, their demand was for energy, not power. For instance, firms that liquefied gases for industrial applications simply needed a total amount of electricity, which they could take at any time: "That is literally just a big storage tank and a compressor. You can run the damn thing whenever you want, right? So it's a perfect example of, if you have time-variant, significantly time-varying rates, you know, and they don't care when they squeeze it, don't the darn thing on when the price is high. Make stuff when the price is low." Kodak's plant in Rochester, another example, consumed power largely for molding plastic parts. But parts could be produced in large quantities overnight for assembly during daytime hours. If Kodak would lobby the utility from which it purchased power to introduce time-varying prices, it could realize savings by shifting its consumption to off-peak and therefore low-cost hours. There were also efforts to develop new techniques of load forecasting that would allow operators to accurately anticipate the responses to spot prices and plan accordingly (David 1988).

Ultimately, no utility implemented spot pricing as described by the Schweppe group. There were a few programs, such as the pilot programs by large California utilities, that adopted a spot pricing algorithm for selected large customers, industrial and commercial firms, in the mid 1980s (Garcia and Runnels 1985). But despite the efforts of Tabors and his associates to promote their concept, it was never adopted as an approach to system-wide control.

The unpredictable feedback loops that would be activated if all power customers, including large industries, reacted to changing prices in real time, were intolerable for system operators whose 
work was premised on a relatively predictable load, prior scheduling of dispatch, and incremental real-time adjustments.

\section{Conclusions}

The market design envisioned by Schweppe and his collaborators, with the spot pricing algorithm at its core, can be understood as a control system with agency distributed between a central calculator and a myriad of independent price-responsive actors. The division of agency, and the construction of the agents themselves, parallels the division of labor between the engineering work to develop the control techniques for state estimation, economic dispatch, and price calculation, and the economic work of modeling the consumer response to price changes and the efficiency of the market design. The particular division of labor put forth by the Schweppe group was ultimately not adopted by the power industry nor supported by regulators. With the advent of regulation in the 1990s, the Schweppe model had even less of a chance. In the one discussion of deregulation in the classic 1988 book, the four authors suggested that the spot pricing system could be extended to a deregulated market by completely severing the price calculator from both buyers and sellers, so that all market participants would be making decisions in response to hourly spot prices. One of the designers who would be involved in the design for wholesale markets that was eventually adopted, describes the reaction to the book's proposal:

The central coordinator would announce the prices and everybody would make their own independent decisions, and then everything would work. And when you discuss this idea with system operators they had a heart attack. They just said, "what are you talking about?" Because they could see the lights going out quite rapidly if we tried to actually implement that. 
The solution, or at least the one currently in place in a large and growing number of power systems internationally, retains the price-calculating approach of the MIT group, but differs in its allocation of agency. As is practiced nearly universally, the central controller, while using using techniques of economic dispatch and price calculation based on those developed at MIT two decades earlier, but within a design that expands the role of central control while circumscribing the agency of the many buyers and sellers. In this design, buyers and sellers submit bids and offers one day in advance of the trading, specifying quantities and prices. The system operator uses the bids to calculate optimal dispatch and the prices that will be charged, based on the lambdas of the dispatch model, for every hour of the following day. Rather than trading for all of the power transacted in real time, most of the transactions have already been determined in the day-ahead market. In real-time, a small amount of power is transacted and prices calculated every five minutes, for deviations from the day-ahead schedule. This is apparently a way of organizing the relationship of central calculation to distributed, marketbased, control, that could satisfy the industry's powerful stakeholders. But once again, it was the underlying equivalence between the optimal allocation and the theoretical market equilibrium that allowed for a reallocation of agency. 


\section{References}

Abur, Ali, and Antonio Gómez Expósito. 2004. Power System State Estimation : Theory and Implementation. Power Engineering 24. New York, NY: Marcel Dekker.

Anderson, Douglas D. 1981. Regulatory Politics and Electric Utilities: A Case Study in Political Economy. Boston, Mass.: Auburn House Pub. Co.

Arrow, Kenneth J. 2008. "George Dantzig in the Development of Economic Analysis." Discrete Optimization, In Memory of George B. Dantzig, 5 (2): 159-67. https://doi.org/10.1016/j.disopt.2006.11.007.

Bennett, S. 1993. A History of Control Engineering, 1930-1955. IEE Control Engineering Series 47. Stevenage, Herts., U.K.: P. Peregrinus on behalf of the Institution of Electrical Engineers, London.

Breslau, Daniel. 2011. "What Do Market Designers Do When They Design Markets? Economists as Consultants to the Redesign of Wholesale Electricity Markets in the U.S." In Social Knowledge in the Making, edited by Charles Camic, Neil Gross, and Michèle Lamont, 379-403. Chicago: University of Chicago Press.

_.2013. "Designing a Market-like Entity: Economics in the Politics of Market Formation." Social Studies of Science 43 (6): 829-51. https://doi.org/10.1177/0306312713493962.

Caramanis, M. C., R. E. Bohn, and F. C. Schweppe. 1982. "Optimal Spot Pricing: Practice and Theory." IEEE Transactions on Power Apparatus and Systems PAS-101 (9): 3234-45. https://doi.org/10.1109/TPAS.1982.317507.

Caramanis, Michael C., Fred C. Schweppe, and Richard D. Tabors. 1983. "Spot Pricing and Its Relation to Other Load Management Methods.” http://dspace.mit.edu/handle/1721.1/60591. 
Cohn, J. 2015. “Transitions from Analog to Digital Computing in Electric Power Systems.” IEEE Annals of the History of Computing 37 (3): 32-43. https://doi.org/10.1109/MAHC.2015.37.

Cohn, Julie A. 2017. The Grid: Biography of an American Technology. Cambridge, MA: The MIT Press.

Dantzig, George B. 1963. Linear Programming and Extensions. [A Rand Corporation Research Study]. Princeton, N.J.,: Princeton University Press.

David, A. K. 1988. “Load Forecasting under Spot Pricing." Transmission and Distribution IEE Proceedings C - Generation 135 (5): 369-77. https://doi.org/10.1049/ip-c.1988.0048.

Dorfman, Robert, Paul A. Samuelson, and Robert M. Solow. 1958. Linear Programming and Economic Analysis. New York: McGraw-Hill.

Freeman, Eva C., and Lincoln Laboratory, eds. 1995. MIT Lincoln Laboratory: Technology in the National Interest. Lexington, Mass: Lincoln Laboratory, Massachusetts Institute of Technology.

Garcia, E. V., and J. E. Runnels. 1985. "The Utility Perspective of Spot Pricing.” IEEE Transactions on Power Apparatus and Systems PAS-104 (6): 1391-93. https://doi.org/10.1109/TPAS.1985.319232.

Garcia-Parpet, Marie-France. 2007. “The Social Construction of a Perfect Market: The Strawberry Auction at Fontaines-En-Sologne." In Do Economists Make Markets? On the Performativity of Economics, edited by Donald A. MacKenzie, Fabian Muniesa, and Lucia Siu, 20-53. Princeton, N.J.: Princeton University Press.

Glaeser, Martin Gustav. 1957. Public Utilities in American Capitalism. New York,: Macmillan. 
Gormley, William T. 1983. The Politics of Public Utility Regulation. Pittsburgh, Pa.: University of Pittsburgh Press.

Grainger, John J., and William D. Stevenson. 1994. Power System Analysis. McGraw-Hill Series in Electrical and Computer Engineering Power and Energy. New York: McGraw-Hill. http://www.loc.gov/catdir/description/mh022/93039219.html http:/www.loc.gov/catdir/toc/mh022/93039219.html.

Guala, Francesco. 2001. "Building Economic Machines: The FCC Auctions.” Studies in History and Philosophy of Science 32 (3): 453-77.

Hausman, William J., and John L. Neufeld. 2011. "How Politics, Economics, and Institutions Shaped Electric Utility Regulation in the United States: 1879-2009.” Business History 53 (5): 723-46. https://doi.org/10.1080/00076791.2011.599589.

Hirsh, Richard F. 1989. Technology and Transformation in the American Electric Utility Industry. Cambridge; New York and Melbourne: http://login.ezproxy.lib.vt.edu/login?url=http://search.ebscohost.com/login.aspx?direct=tr $\mathrm{ue} \& \mathrm{db}=\mathrm{eoh} \& \mathrm{AN}=0237485 \&$ site $=$ eds-live $\&$ scope $=$ site 1999. Power Loss : The Origins of Deregulation and Restructuring in the American Electric Utility System. Cambridge, Mass.: MIT Press.

Hughes, Thomas P. 1983. Networks of Power: Electrification in Western Society. Baltimore: Johns Hopkins University Press.

—. 1987. “The Evolution of Large Technological Systems.” In, edited by Wiebe E. Bijker, Thomas P. Hughes, and Trevor Pinch. Cambridge, Mass.: MIT Press.

Joskow, Paul L., and Richard Schmalensee. 1983. Markets for Power : An Analysis of Electric Utility Deregulation. Cambridge, Mass.: MIT Press. 
Lambert, Jeremiah D. 2015. The Power Brokers: The Struggle to Shape and Control the Electric Power Industry. 1 online resource (xiv, 379 pages) : illustrations. vols. Cambridge, Massachusetts ; The MIT Press. EBSCOhost http://search.ebscohost.com/login.aspx?direct=true\&scope $=$ site $\& d b=$ nlebk $\& d b=$ nlabk\&A $\mathrm{N}=1058793$.

Lerner, Abba Ptachya. 1947. The Economics of Control; Principles of Welfare Economics. New York: The Macmillan company.

Lifset, Robert D. 2014a. "A New Understanding of the American Energy Crisis of the 1970s." Historical Social Research / Historische Sozialforschung 39 (4 (150)): 22-42.

- 2014b. "A New Understanding of the American Energy Crisis of the 1970s." »Eine Neue Interpretation Der U.S.-Amerikanischen Energiekrise Der 1970er Jahre«. 39 (4): 22-42. https://doi.org/10.12759/hsr.39.2014.4.22-42.

MacKenzie, Donald. 1990. Inventing Accuracy: A Historical Sociology of Nuclear Missile Guidance. Cambridge, Mass.: MIT Press.

Neufeld, John L. 1987. "Price Discrimination and the Adoption of the Electricity Demand Charge." The Journal of Economic History 47 (3): 693-709.

Nik-Khah, Edward. 2008. “A Tale of Two Auctions.” Journal of Institutional Economics 4 (1): 73-97.

Reynolds, S. P., and T. E. Creighton. 1980. “Time-of-Use Rates for Very Large Customers on the Pacific Gas and Electric Company System.” IEEE Transactions on Power Apparatus and Systems PAS-99 (1): 147-51. https://doi.org/10.1109/TPAS.1980.319621.

Roth, Alvin E. 2002. “The Economist as Engineer: Game Theory, Experimental Economics, and Computation as Tools of Design Economics." Econometrica 70 (4): 1341-78. 
Schweppe, F. C., R. D. Tabors, J. L. Kirtley, H. R. Outhred, F. H. Pickel, and A. J. Cox. 1980. “Homeostatic Utility Control.” Power Apparatus and Systems, IEEE Transactions On PAS-99 (3): 1151-63. https://doi.org/10.1109/TPAS.1980.319745.

Schweppe, Fred C., Michael C. Caramanis, Richard D. Tabors, and Roger E. Bohn. 1988. Spot Pricing of Electricity. Kluwer International Series in Engineering and Computer Science, SECS 46 Power electronics \& power systems. Boston: Kluwer Academic.

Schweppe, Fred. C., and J. Wildes. 1970. "Power System Static-State Estimation, Part I: Exact Model." IEEE Transactions on Power Apparatus and Systems PAS-89 (1): 120-25. https://doi.org/10.1109/TPAS.1970.292678.

Stahl, E.C.M. 1931. "Economic Loading of Generating Stations.” Electrical Engineering 50 (9): 722-27. https://doi.org/10.1109/EE.1931.6429418.

Wiener, Norbert. 1948. Cybernetics, or, Control and Communication in the Animal and the Machine. New York: Wiley and Sons.

Wu, Felix F. 1990. "Power System State Estimation: A Survey.” International Journal of Electrical Power \& Energy Systems 12 (2): 80-87. https://doi.org/10.1016/01420615(90)90003-T.

Yakubovich, Valery, Mark Granovetter, and Patrick McGuire. 2005. "Electric Charges: The Social Construction of Rate Systems." Theory \& Society 34 (5/6): 579-612. 